\title{
Situación actual de los derechos del pueblo mapuche después del caso Catrillanca
}

\section{Introducción}

El 14 de noviembre de 2018, el país fue conmocionado con la noticia de que había muerto un joven mapuche, Camilo Catrillanca, a manos de efectivos de Carabineros. Camilo era hijo del presidente de la Comunidad Ignacio Queipul Millanao y nieto del conocido lonko Juan Catrillanca. Cuando murió tenía una hija de seis años y su pareja estaba embarazada.

Después de un conjunto de informaciones confusas y diversas versiones del Ejecutivo, en el que se vinculaba al joven Catrillanca con el robo de unos automóviles, se indicaba que tenía antecedentes criminales o que su muerte habría ocurrido en medio de un tiroteo, salió a la luz que este joven murió por un balazo en la espalda, dirigido a la cabeza, mientras regresaba en un tractor a su casa en compañía de un adolescente, quien presenció la muerte de Camilo y recibió malos tratos policiales, los que después fue investigado como tortura. No se acreditó el tiroteo y ninguna vinculación de Catrillanca a alguna actividad delictiva.

El caso de Camilo Catrillanca se añade a una lista no menor de jóvenes mapuches muertos en reales o supuestos enfrentamientos con efectivos policiales del Estado chileno, la mayoría de ellos en el contexto de represión de protestas. Sumado al caso de los Luchsinger, de enero de 2013, el caso Catrillanca es emblemático del nivel de violencia a que ha llegado la conflictividad en la zona sur y del deterioro de las relaciones interculturales.

Esta situación da cuenta, al menos, de una deformación en cómo un Estado democrático puede tratar de enfrentar y resolver problemas históricos derivados de la colonización de los pueblos indígenas, como de su discriminación y marginación persistente en la actualidad. La carencia de instituciones que logren abordar democráticamente los problemas y tensiones étnicas, de derechos que brinden legitimidad a las formas de convivencia, garantizando la sobrevivencia cultural y desarrollo au-

\footnotetext{
1. Lonko, lonco o longko consiste en el rol social directivo de una comunidad o lof. Es la autoridad política básica de las comunidades mapuches, y sirve como su cabecilla, mediador y portavoz.
} 
tónomo del pueblo mapuche, en armonía con los derechos humanos de los demás, así como la ineficacia de muchas políticas públicas, ha llevado a que las relaciones interculturales se hayan convertido en una fuente permanente de vulneraciones a derechos fundamentales, así como en un foco estable de observación de los sistemas de protección internacional de los derechos humanos.

\section{Pregunta 1. Caso Catrillanca}

¿Qué implicancias tiene el caso Catrillanca para las relaciones entre el pueblo mapuche y el Estado y la sociedad chilena?

\section{Margarita Calfío}

Se ha marcado un tremendo quiebre, un abismo entre el actual gobierno y el pueblo mapuche, en definitiva, producto de la enorme violencia incubada por el Estado en décadas de allanamientos, robos, montajes y represión militar.

El asesinato del joven Camilo Catrillanca Marin y las torturas y amenazas sufridas por el menor que lo acompañaba en las faenas agrícolas que hacían en un tractor de propiedad comunitaria, era algo que se venía venir con la instalación del denominado comando jungla en Wallmapu. ${ }^{2}$ Un comando formado en la selva colombiana para torturar y matar. No hay diálogo fecundo en estos contextos de odio y represión.

Cómo hoy se va a confiar en un gobierno que por un lado pregona paz y, por debajo, invierte muchos millones de dólares en represiones brutales y cobardes, asesinatos por la espalda a jóvenes, torturas y amenazas a niños, golpes e insultos a mujeres, montajes, destrucción de evidencias, robos de antiguas joyas de herencia de mujeres, y otras situaciones.

El momento histórico que estamos afrontando es muy duro. El racismo más vil se ha instalado con impunidad en esta frontera, una marca que nos divide, que nos estigmatiza y que nos duele profundamente, porque nuestro pueblo ama la vida y estamos luchando por que prevalezca frente a la injusticia y los malos gobiernos.

Camilo Catrillanca Marín fue asesinado por la espalda con un balazo en su cabeza percutido por Carlos Alarcón, miembro del comando Jungla. Camilo era un joven muy querido por su lof, ${ }^{3}$ nieto de Juan Catrillanca, lonko muy conocido y respetado,

\footnotetext{
2. Nombre indígena del conjunto del territorio habitado históricamente, en diversos grados, por el pueblo mapuche.

3. El lof o lov es el conjunto de familias mapuches emparentadas y que comparten un territorio, lo que constituye la unidad básica de la estructura social mapuche, así como el territorio en que habitan o habitaban. Es la comunidad histórica o tradicional mapuche.
} 
que se destaca por ser sabio y dialogante. Él ha liderado procesos de recuperación de tierras incluso mediante la ley indígena, logrando acuerdos y avances con el exdirector de la Conadi, Jorge Retamal Rubio.

Por tanto, se traicionó la voluntad de avanzar de forma real. Fue una cobardía de parte de Carabineros, mintieron y destruyeron pruebas valiosas, la institución de Carabineros sigue enlodando su reputación. ¿Quién nos defiende de estos atropellos? La justicia chilena pareciera ser una tómbola intervenida para favorecer al capital y dañar al pueblo mapuche.

\section{Venancio Coñuepan}

Primero, hay que preguntarse qué tipo de relación existe entre el pueblo mapuche y el Estado chileno. A mi juicio, esta relación en las últimas décadas ha sido de tipo colonial, una dominación impuesta por parte de la sociedad chilena a nombre de una supuesta superioridad cultural que nos trae el «desarrollo y la paz» al pueblo mapuche. Por cierto que existen ciertos momentos de indigenismo simulado, como el Acuerdo de Nueva Imperial en 1989, la Comisión Verdad Histórica y Nuevo Trato del 2003, los distintos programas de gobierno de todos los presidenciables, la Comisión Asesora Presidencial de Bachelet en el 2016 o el Acuerdo Nacional por el Desarrollo y la Paz en La Araucanía de Piñera en el año 2018. Pero dichas políticas no son más que la perpetuación, expansión y negación de la autodeterminación del pueblo mapuche.

En ese marco, el caso Catrillanca no significó ningún cambio en la relación entre el pueblo mapuche y el Estado chileno, tan solo ratificó y dejó en evidencia la situación colonial, la represión policial, el indigenismo simulado de los gobiernos de turno y la constante persecución a las autoridades tradicionales, líderes y organizaciones del pueblo mapuche.

Una verdadera relación es la que tenían nuestros abuelos con los españoles o con los padres de la Republica chilena hasta mediados del siglo XIX, diferentes relaciones que eran reguladas a través de los diversos koyang ${ }^{4}$ o parlamentos que suscribían las autoridades españolas o chilenas con las distintas autoridades mapuches, instrumentos en que se regulaban aspectos sociales, políticos, económicos, jurídicos y militares de la relación entre los mapuches y sus otros. Muy por el contrario, en el Chile de hoy, tan solo tenemos una reacción de ciertos sectores del pueblo mapuche a las diferentes políticas coloniales de los gobiernos de turno.

4. Koyang, koyag o coyag consiste en una reunión ceremonial de la sociedad mapuche para interactuar de forma interna, como también para la interacción con los otros (espñoles, chilenos y argentinos), en la que tomaban parte principalmente los jefes políticos o lonkos. 
Donde debiese haber generado un cambio el cruel asesinato del peñi Camilo Catrillanca es en la percepción y la valoración que tenemos que hacer del trabajo, la palabra y sobre todo del rol que tiene Carabineros de Chile en el marco del conflicto chileno-mapuche; ya que nunca había quedado tan de manifiesto el desprecio, la negligencia, la mentira, la burla y el abuso de fuerza innecesaria que normalizan y ejercen algunos carabineros en contra de miembros del pueblo mapuche.

El caso del peñi Catrillanca no es aislado: se trata a lo menos de la cuarta víctima conocida en supuestos enfrentamientos contra carabineros. Ya lo fueron Alex Lemun Saavedra en el año 2002, Matías Catrileo en el año 2008 y Jaime Mendoza Collio en el año 2009.5 Hoy los mapuches no tenemos ninguna obligación de creer en la buena fe de Carabineros cuando se trata de relaciones o enfrentamientos con comunidades indígenas o representantes del pueblo mapuche. Por otro lado, el gobierno de Sebastián Piñera, y en particular las autoridades del Ministerio de Interior, nunca asumieron su responsabilidad en el asesinato del peñi Catrillanca. Por el contrario, continúan con una supuesta política de «restablecimiento del Estado de derecho», que no es más que la violación de los derechos humanos del pueblo mapuche, la negación de sus reivindicaciones históricas y la promoción de una ley corta antiterrorista que colisiona directamente con el debido proceso.

\section{Verónica Figueroa}

Creo que el caso Catrillanca marcó un antes y un después, pero también al ver esa problemática en contexto, o sea, no nos olvidemos que no es la primera muerte que ocurre en democracia y que de alguna manera es producto de una política de militarización de la Araucanía que se viene implementando desde hace ya varias décadas y que ha sido la política de los distintos gobiernos, independientemente de su ideología política. Todos han mantenido la misma práctica con los pueblos indígenas y en particular con el pueblo mapuche.

Ahora, concretamente con el caso de Camilo Catrillanca, existe la particularidad de que, a diferencia de lo sucedido en los asesinatos anteriores - como, por ejemplo,

5. Edmundo Alex Lemun Saavedra fue un estudiante mapuche, perteneciente a la comunidad Requen Lemún Bajo, que murió a los 17 años, el 12 de noviembre de 2002, por un impacto de bala en la cabeza disparado por un efectivo de Carabineros, en el contexto de un acto de ocupación de terrenos realizada por parte de la comunidad Montutui Mapu en el fundo Santa Elisa de Forestal Mininco; Matías Valentín Catrileo Quezada fue un estudiante universitario mapuche, muerto a los 22 años, el 3 de enero de 2008, por un disparo con una subametralladora Uzi por un efectivo de Carabineros, en el contexto de la ocupación del exfundo Santa Margarita; Jaime Facundo Mendoza Collio, joven mapuche, murió a los 24 años, el 12 de agosto de 2009, por un disparo de un efectivo de Carabineros, en el contexto de la ocupación del fundo San Sebastián. 
de Matías Catrileo, Alex Lemun, de Jaime Mendoza Collio, entre otros-, siempre se habían dado en contextos de enfrentamiento de reivindicación de distintas comunidades sobre territorios que estaban reclamando o que estaban en manos de latifundistas o manos de privados. Sin embargo, la muerte de Camilo marca una diferencia, porque de alguna manera también puso en tela de juicio a una institucionalidad, que de hecho ya se encontraba cuestionada por la operación Huracán.

Esta institucionalidad ha sido clave en la relación del Estado con el pueblo mapuche, en particular Carabineros de Chile, que ha sido el instrumento que ha utilizado el Estado para tener un control. Un control del territorio, un control de la seguridad del territorio y sobre todo, yo diría, una política y un control de brindar seguridad a las empresas extractivas y productivas que se encuentran en la zona. No tiene que ver con proteger a la ciudadanía, ni a las comunidades ni la convivencia, sino que tiene más que ver con asegurar un funcionamiento continuo de la extracción que se produce en esa zona.

Finalmente, creo que marcó un antes y un después porque demostró y dejó muy latente cómo la institucionalidad del Estado, la cual se supone se basa en la confianza, porque le dan el uso legítimo de la fuerza, de la fuerza física, marca un hito, porque demuestra que las personas que componen la institución y la institución en sí no eran dignas de esa confianza, ya que por lo demás manipularon hechos, manipularon datos, manipularon información, manipularon protocolos, mintieron de manera descarada y, de alguna manera, autoridades políticas se hicieron parte de esas mentiras, repitieron un discurso basado no en evidencias sino en las mentiras que después poco a poco se fueron aclarando.

Todo eso dejó en evidencia lo inhumano e irrespetuoso del trato. Considero que todos quienes vimos las imágenes apreciamos la dureza del trato, del momento en que estaba Camilo agonizando, la poca consideración del menor que acompañaba a Camilo, que fue esposado, que fue torturado y llevado sin ningún tipo de protección de lo que establece tanto en la normativa nacional o internacional en términos de protección de derechos, de derechos de la infancia y de los niños. ${ }^{6}$

Entonces, todos estos ingredientes hicieron que el caso de Camilo marcara un antes y un después. Estimo que la sociedad civil también comienza a empatizar. $\mathrm{Si}$ bien todavía le cuesta mucho entender y comprender las reivindicaciones del pueblo mapuche en particular, el caso sí planteó una situación en que la vulneración de los derechos de los pueblos indígenas y la crudeza de su muerte y la manipulación que se hizo posterior, demostró que no hay ningún ánimo del Estado chileno por cambiar.

6. Véase “¿Querís que te mate como a tu peñi?”: El desgarrador relato de lo que sufrió el menor que acompañaba a Catrillanca», Chilevisión Noticias, 10 de marzo de 2019, disponible en http://bit. ly/2K6wghU. 
La muerte de Camilo para el Estado no supuso ningún cambio estructural, ningún cambio en las decisiones; muy por el contrario, se ha decidido continuar en la lógica de la seguridad, de la militarización, de castigar al pueblo mapuche y a sus representantes. Resulta muy doloroso aquello para quienes nos sentimos y somos mapuches y somos testigos de esa vulneración, porque para el Estado la política indígena no es un tema en su agenda, nunca lo ha sido.

\section{Pregunta 2. Libre determinación y autonomía indígena}

¿Cómo entiende usted la libre determinación, la autonomía y el autogobierno indígena? ¿Cuáles son sus posibilidades de implementación en Chile?

\section{Margarita Calfío}

La libre determinación es reconocida como derecho en la Declaración de Naciones Unidas sobre los Derechos de los Pueblos Indígenas. En su artículo 3 establece que los pueblos indígenas tienen derecho a la libre determinación. En virtud de este derecho, determinan su condición política y persiguen libremente su desarrollo económico, social y cultural. Luego, el artículo 4 establece que los pueblos indígenas, en ejercicio de su derecho a la libre determinación, tienen derecho a su autonomía o al autogobierno en las cuestiones relacionadas con sus asuntos internos y locales, así como a disponer de medios para financiar sus funciones autónomas.

En este sentido, el derecho a la libre determinación la entiendo como la libertad de ser lo que somos, y lo que queremos proyectar como pueblo, espacios propios de educación y recreación mapuche. Por ejemplo, espacios en que se hable el idioma desde la primera infancia. Que podamos vestir libres, que contemos con sistemas interconectados entre la tradición mapuche y las nuevas tecnologías. Por ejemplo, en salud, la complementariedad entre el saber de las personas y las medicinas, con apoyo de universidades para obtener plantas medicinales que se encuentran en pocas cantidades.

Las posibilidades para su implementación en la actualidad no existen, porque la visión política imperante no es cercana a estos reconocimientos, porque en la práctica es ejercer poder de decisión sobre la vida. A nivel de la ciudadanía en general, falta un cambio de paradigma, formación y prácticas institucionales desde un enfoque de derechos y desarrollo de competencias interculturales. Esto ha sido desarrollado por la Unesco y son procesos que deben implementarse a nivel nacional por el contacto intercultural, que son hechos cotidianos. Las personas no nacen interculturalmente competentes, se vuelven competentes a través de la educación y las experiencias vitales. 


\section{Venancio Coñuepan}

Primero, hay que distinguir entre lo mapuche y lo indígena. De los pu lonko, ${ }^{7} p u$ machi, ${ }^{8}$ pu ngenpin ${ }^{9} \mathrm{y}$ a través de los pewma,${ }^{10}$ he aprendido que para algunos lo mapuche es algo más espiritual, es la conexión que tiene el $c h e^{11}$ con la $m a p u,{ }^{12}$ que es una conexión difícil de describir pero que, según el ngenpin Armando Marileo, es la consciencia de ser una parte integrante de la naturaleza y el resultado de esa fusión entre energía y materia también posee y trae consigo fuerzas que las equilibran, es decir, está compuesto también por el küme newen ${ }^{13}$ y el weda newen, ${ }^{14}$ energías que permiten mantenerse en la balanza que se produce cuando el che y su entorno natural -su mapu- está en equilibrio. Es decir, para que el che esté en equilibrio y en armonía, necesariamente debe estar en equilibrio y armonía con su mundo natural, su entorno social, cultural, territorial, pero también es fundamental el equilibrio en su mundo espiritual, y ello conlleva un balance y equilibrio entre su mente, cuerpo, emociones, lo que provoca el küme felen. ${ }^{15}$ Marileo dice que quizás por esta razón el che se autodenominó «mapu-che», por cuanto asumió la responsabilidad de ser integrante, miembro e hijo de la tierra y naturaleza, por ende, hermano de todos aquellos elementos que componen el mapu. A su vez, asumió la condición en la protección de éstos.

Esta concepción del mapuche es la que he visto vivenciar en un gran número de pu peñi ${ }^{16} \mathrm{y}$ pu lamgen, ${ }^{17}$ que quizás no están en el ámbito público de las relaciones chileno-mapuche, pero son estos zulliñ che ${ }^{18}$ los que tienen influencia real en los terri-

7. Plural de lonko.

8. Plural de machi. La machi es una autoridad espiritual del pueblo mapuche que ejercía funciones de curación física y espiritual en la medicina mapuche. Era el vínculo principal entre el mundo sobrenatural de espíritus y deidades y el mundo humano.

9. Plural de ngenpin, ñenpin o ngenpiñ. El ngenpin o dueño de la palabra es una autoridad políticoreligiosa mapuche que asesora sobre espiritualidad, ciencia y sabiduría ancestral mapuches, y es el responsable de proyectar y proteger dichos conocimientos de la cosmovisión mapuche.

10. Sueño. Para los mapuche, lo onírico proporciona pautas para seguir en la vida cotidiana, pues los pewma son espacios en los cuales el mundo sagrado se comunica con los humanos.

11. Che es la persona o gente.

12. Mapu es la tierra o el conjunto del espacio natural donde se habita

13. Energías positivas.

14. Energías negativas.

15. Estar bien, en armonía o equilibrio.

16. Plural de peñi. Peñi significa hermano, y constituye el tratamiento cordial a cualquier varón mapuche.

17. Plural de lamgen. Lamgen significa hermana, y constituye el tratamiento cordial a cualquier mujer mapuche, aunque también designa a un hombre cuando está en compañía de mujeres.

18. Personas elegidas. 
torios mapuches, pues ellos mantienen la «importancia especial» de la «relación con las tierras o territorios» a que hace referencia el Convenio 169 de la OIT en su artículo 13. Son ellos los que comprenden y respetan a los newen, ${ }^{19}$ los ngen, ${ }^{20}$ los ngünen $;{ }^{21}$ lo demás es mera prensa o ideología.

No obstante lo anterior, considero que no existe un solo pueblo mapuche, hay una suerte de «nación de naciones», en que conviven diversas manifestaciones del pueblo mapuche tradicional con sus variaciones históricas, lingüísticas, económicas, políticas, culturales, etcétera, según la identidad territorial a la que correspondan (wenteche, nagche, pewenche, lafkenche, etcétera ${ }^{22}$ y la diferente forma en cómo se relacionan esos che con su mapu. Por otro lado, al menos desde 1911, con la creación de la Sociedad Caupolicán Defensora de La Araucanía, tenemos un «movimiento civil indígena-mapuche» que, con matices, más o menos mezclan lo tradicional mapuche y lo contemporáneo indígena, un grupo que muchas veces tiene relación con el primero y entiende la existencia entre el che y la mapu, pero a veces no vivencian dicha relación o la pasan por algo anecdótico, un mito fundacional. En tercer lugar, existe un grupo formado por personas descendientes de mapuches, que mantienen alguna conexión, ya sea a través de un predio, un apellido, una historia familiar, un objeto cultural, etcétera, pero que en muchas ocasiones no entienden la conexión entre el che y la mapu, e incluso algunos asimilan lo mapuche a lo indígena y creen que ser mapuche es lo mismo que ser aimara, rapa nui, chiapa o un revolucionario anticapitalista.

La diferenciación anterior nos puede ayudar a responder mejor la pregunta de fondo sobre autodeterminación, autonomía y autogobierno. Primero, en relación al pueblo mapuche tradicional, que concibo como una suerte de «nación de naciones», con un mapuche kimün ${ }^{23}$ transversal, naciones que van desde el océano Atlántico al Pacífico, naciones que se manifiestan a través de lof en particular o alianzas de distintos lof o identidades territoriales. Este pueblo mapuche más tradicional, en cierto modo, nunca ha dejado de ejercer su autodeterminación, en sus territorios existen pu lonko, pu werkenes, ${ }^{24}$ pu machi, pu ngenpin, pu ülmen, ${ }^{25}$ entre otras autoridades.

\footnotetext{
19. Fuerzas.
}

20. Ngen se refiere genéricamente al dueño de alguna entidad. Se refiere a espíritus de la naturaleza en la cosmovisión mapuche, que dominan, predominan, mandan, gobiernan y disponen sobre algún elemento natural, al que también cuidan, protegen y resguardan.

21. Deidades, Voluntades raiz, protectores, protectores y originadores.

22. Identidades mapuches vinculadas a territorios específicos (lafkenmapu: marítimos, rivereños y lacustres; nagmapu: llanos; wentenmapu: colinas, lomas o valles; pewenmapu: donde están los pewenes o araucarias, cordilleras).

23. Sabiduría y conocimientos mapuches.

24. Plural de werken. Werken es una autoridad tradicional de índole política que aconsejaba al lonko y fungía de portavoz de la comunidad y de los lonkos llevando mensajes a otros.

25. Plural de ülmen. Ülmen es una persona influyente en un territorio, debido a su sabiduría o riqueza. 
En dichos territorios, estas autoridades aún conservan cierta potestad y un rol dentro de las naciones del pueblo mapuche. Son territorios reducidos geográficamente, pero en esos márgenes poco importan los 150 años de historia del Estado chileno en ngülumapu, ${ }^{26} \mathrm{o}$ los 300 años de la colonia española: siguen los pu lonko, siguen las y los machi, siguen las ceremonias, sigue el vínculo de che con la mapu, sigue el respeto a los ngen, a los newen y ngünen; sigue el mapuche kimün. El mundo mapuche tradicional no necesita del Estado para el reconocimiento del derecho a la autodeterminación, porque ése es un derecho que de una u otra forma han estado ejerciendo desde hace siglos; por el contrario, es la defensa de otro tipo de derechos más específicos, como la libertad personal, derechos lingüísticos y culturales, consulta y participación indígena, respeto por los territorios indígenas, participación en los beneficios, etcétera, que, de no mediar positivización de parte del Estado, lo único que queda es la vía judicial tanto nacional como internacional.

Por otro lado, el pueblo contemporáneo es un pueblo más indígena que mapuche. Son personas y organizaciones indígenas que en no pocas veces confunden o tergiversan los fundamentos del mapuche kimün, con lo que irónicamente estarían violando la autodeterminación del pueblo mapuche tanto como lo hace el Estado chileno. Desde el mundo mapuche tradicional, desde el $a z$ mapu, ${ }^{27}$ se entiende que cada espacio tiene su propia identidad que influye en el ordenamiento que cada lugar pueda tener. Por ejemplo, los lafkenche ligan sus energías hacia el lafken (mar), ${ }^{28}$ a diferencia de los wenteche, que tienen una conexión con las wentes (lomas). De esa manera, esos mapuches se relacionan con su entorno de diferente forma. Por ende, no sería problema el surgimiento de este mundo mapuche más contemporáneo si es que existiese respeto recíproco, surgieran nuevas normas, nuevas formas de entender el mundo, nuevas autoridades o prácticas sociales, tal como ha ocurrido hace cientos de siglos en nuestro territorio.

El problema surge cuando ciertos grupos de este mundo indígena contemporáneo, y sobre todo desde el Estado, conciben la autonomía y el autogobierno de una forma colonial, unilateral y homogénea. Que es lo que está pasando hoy con organizaciones como la Coordinadora Arauco-Malleco (CAM), que, si bien señalan por un lado que no representan a todo el pueblo mapuche ${ }^{29}$ por otro lado toman acción en todo el territorio a nombre de todo el pueblo mapuche.

Finalmente, entre estos tres conceptos existe una relación de genero-especie, en la que libre determinación o autodeterminación es el derecho que tienen los pueblos

26. Territorio ancestral mapuche al oeste de la cordillera de los Andes.

27. Sistema normativo propio del pueblo mapuche.

28. Lafkenmapu constituía el conjunto de los espacio marítimos, fluviales y lacustres.

29. Patricio Fernández, «Héctor Llaitul, mapuche, anticapitalista y revolucionario: "No represento a todo el pueblo nación mapuche"», The Clinic, 19 de mayo de 2019, disponible en http://bit.ly/2YnjSDl. 
para determinar libremente su condición política y perseguir libremente su desarrollo económico, social y cultural.

Ahora bien, la libre determinación puede manifestarse de diversas formas. Una de ellas es la autonomía indígena, entendida como la posibilidad que tienen los pueblos indígenas para implementar esta autonomía ya sea en lo cultural, económico, social o político. Por último, el autogobierno es una especificación de la autonomía indígena relativa a la soberanía de los pueblos.

El pueblo mapuche tradicional, dentro de sus posibilidades, ha ejercido sus derechos de autodeterminación, autonomía y autogobierno dentro de sus territorios. El problema surge porque en los últimos años han aparecido amenazas contra esos territorios que están perturbando esos derechos. En esta defensa de los territorios mapuches, hoy juegan un importante rol los miembros del movimiento civil indígena-mapuche, que a través de diversas instancias políticas, públicas y jurídicas están promoviendo la defensa de nuestros territorios.

\section{Verónica Figueroa}

En primer lugar, considero que son derechos que están reconocidos en las normas internacionales. Además, están reconocidos en pactos y convenios que Chile ha suscrito como Estado. Por lo tanto, el derecho de la libre autodeterminación, como lo establece la normativa y el derecho que tienen los pueblos en cuanto pueblos a decidir de manera autónoma cómo quieren vivir su vida, cómo se proyectan dentro de este espacio territorial. La autonomía entendida como la posibilidad de tener su propia institucionalidad, su propia posibilidad de ejercer un derecho de tipo consuetudinario, de tener sus propios mecanismos de aplicación de justicia, su propio mecanismo de elaboración de normas, basados en este caso en el az mapu. En este punto es importante aclarar que no es cierto que el pueblo mapuche no tenga normas o que no tenga institucionalidad, porque sí las tiene. Lo que sucede es que este Estado occidental invisibilizó y nunca consideró esa institucionalidad como un elemento relevante o para ser incorporado dentro de su norma.

Dentro de este ejercicio de poder ser y ejercer la autonomía, la autodeterminación, el autogobierno, es muy relevante definir cuáles son los mecanismos mediante los cuales se podría ejercer la autoridad política como un derecho que tienen los pueblos.

Esos tres conceptos, que están tan entrelazados, claramente constituyen un desafío fundamental en el caso de todos los Estados-nación, en primer lugar porque son Estados que diseñaron toda esta institucionalidad desde la lógica occidental. En esta lógica, el derecho basado en la lógica territorial, en el equilibrio con el mundo material y el mundo inmaterial, es incomprensible para este mundo dicotómico occidental y, por lo tanto, las posibilidades de reconocer, de dar ejercicio a la libre autode- 
terminación, a la autonomía y al autogobierno, que tanto asusta al mundo occidental, tienen pocas posibilidades de ser ejercidos en plenitud, porque sería bajo las reglas del juego occidental.

Pienso que un término medio o un avance sustantivo sería conversar cómo ponemos sobre la mesa una discusión que considere todos estos aspectos, entendiendo que hay que remecer las reglas del juego en las que se ha sustentado la vida en este territorio y esta sociedad. Eso es algo precisamente que las élites políticas - y yo diría también que la sociedad civil en general- no están dispuestas a hacer, porque cuando entramos al área chica y definimos qué es lo que queremos hacer, y suponiendo que queremos avanzar en estos derechos de manera paulatina, nos entrampamos. Chile debiera, en primer lugar, reconocer constitucionalmente a los pueblos indígenas, ahora en una constitución wingka $a^{30}$ y occidental, que de hecho intente acomodar el ejercicio de estos derechos al paragua institucional, político-administrativo que ya existe en Chile y, por lo tanto, ya estamos partiendo desde el ejercicio bien acotado que - desde mi punto de vista, en esta lógica - tendrían estos pueblos para ejercer esos derechos.

En segundo lugar, cómo esos tres elementos de alguna manera en este modelo republicano y de equilibrio de poderes tiene una expresión ya no tan solo en la Constitución, sino también en el Poder Legislativo, en el Ejecutivo y en el Judicial, que empieza de alguna manera a remecer los pilares en los cuales se han construido estos tres poderes y en la lógica en la cual se agrega en Chile de un hiperpresidencialismo con un Ejecutivo con mucho poder para legislar de igual forma.

En tercer lugar, diría son conceptos muy desconocidos y, como son desconocidos en el sentido de la sociedad y la élite política, tienden incluso a asustarse mucho con ellos, catalogándolos como "germen de la destrucción del Estado», ya que con éstos, desde su punto de vista, se estarían rompiendo las bases de la República, lo que nos lleva a decir que en la ignorancia está el gran peligro de no poder avanzar en su implementación. Esto es a pesar de la existencia de numerosas publicaciones de académicos y académicas mapuches que hablan sobre el tema y explican los conceptos.

Chile todavía está muy lejos de avanzar en estos términos, porque no existe un reconocimiento de pueblos en nuestra legislación, no hay un ministerio, no hay reconocimiento constitucional, no hay una voluntad de romper con la lógica occidental, no hay posibilidad ni voluntad de poner en la agenda de discusión desde la propia lógica de los pueblos indígenas - no solo mapuche, del resto de los ocho pueblosque se encuentran en este territorio de discutir los acuerdos de este Estado.

Recuerdo que cuando se inició el Plan Araucanía y se planteó la posibilidad de una ley de cuotas indígenas, lo primero que surge es que la ley de cuotas es muy sim-

30. Wingka, winka o huinca se refiere a quienes no son mapuches. Concepto comúnmente aplicado a los invasores, que vienen a los territorios mapuches a conquistar, despojar y robar tierras. 
bólica, avanzamos hacia la idea de los escaños reservados, y cuando comenzamos a poner cifras a esos escaños reservados, nos preguntamos cuántos serían: ¿diez, veinte? Se aprecia que cuando se comienza a poner cifras o en definitiva a concretar el dato, la gente tiende a asustarse y a cuestionar los posibles avances.

Pienso que esto se debe a la falta de educación, ya que somos una sociedad que desconoce a los pueblos indígenas y los desconoce absolutamente. No hemos aprendido nada de los pueblos indígenas, salvo algunas cosas anecdóticas en los colegios, no hay un aprendizaje. Ello se traduce lógicamente en no saber relacionarse con algo que no se conoce y que, de hecho, en el inconsciente no ha sido valorado o no forma parte de la cotidianidad. Por lo tanto, todavía hay mucho trabajo por hacer. No es imposible, creo que se están dando pasos hacia ello, pero sin duda es un camino de largo plazo.

\section{Pregunta 3. Derechos mapuches y empresas}

¿Cómo se han comportado las empresas privadas nacionales y extranjeras respecto de los derechos humanos del pueblo mapuche?

\section{Margarita Calfío}

En general las empresas privadas nacionales y extranjeras no observan protocolos para el respeto de los derechos humanos del pueblo mapuche. Por tanto, es importante generar mecanismos que permitan un trabajo coordinado a largo plazo, involucrando a las familias, comunidades, empresas y Estado, como garante de las acciones que se desarrollen.

Sabemos que la perspectiva de los derechos humanos desde lo conceptual a la encarnación en las personas mapuche, en este caso específico, constituye un desafío transversal para todo el país, incluidas las empresas que en general no observan y no se relacionan con sus vecinos.

En general, las empresas forestales en estos territorios han venido a depredar la naturaleza, a empobrecer los territorios y a contaminar las aguas, el aire, la vida.

\section{Venancio Coñuepan}

Es difícil emitir un juicio en relación de las empresas y el pueblo mapuche, porque las primeras y los segundos son muchísimos y muy diferentes entre sí. Pero según mi experiencia, puedo comentar algunas cosas.

Primero, entre las empresas privadas nacionales hay que hacer varias distinciones, entre empresa mapuche y empresa de mapuches, empresas chilenas regionales y empresas nacionales; empresas con conflictos de interés y empresas sin conflictos de interés. Lo mismo ocurre con las empresas privadas extranjeras, principalmente si tienen conflictos de intereses. 
Las «empresas mapuches» son muy pocas, una de las que conozco es Taiñ Lawentuwün $\mathrm{SpA}$, una empresa de propiedad de autoridades tradicionales mapuches ( $p u$ machi, lonko, ngenpin, etcétera) en el que su rubro (salud mapuche, no salud intercultural) y gobernanza interna tiene como eje el mapuche kimün y el mapuche lawentuwün. ${ }^{31}$ Es una «empresa mapuche» porque dentro de los estatutos de constitución de la empresa, y aprovechando la flexibilidad que tienen las sociedades por acciones, los socios incorporaron normas propias del az mapu.

Donde sí existe mucha presencia es en las «empresas de mapuches», que son aquellas de propiedad de personas indígenas. La diferencia con las anteriores es que muchas veces estas empresas tienen ciertos elementos que evocan lo mapuche, como nombres, logos, una historia, etcétera, pero en su funcionamiento no difieren mucho de una empresa chilena, con excepción de las limitaciones a las que están expuestas las personas indígenas por la Ley 19.253.

En cuanto a las empresas chilenas, sean regionales o nacionales, el problema no es su rubro ni su dueño, sino el conflicto de interés que tienen con el pueblo mapuche, principalmente la disputa de los territorios y recursos naturales. Los predios de Forestal Mininco podrían ser todos estatales o destinados no al rubro forestal e igual se mantendría el conflicto, porque lo que se disputa es la titularidad de esos territorios. $Y$ esa titularidad territorial no es reconocida por el Estado chileno y, por tanto, cuando la empresa considera que los mapuches violan su "propiedad privada», utilizan las herramientas que el ordenamiento jurídico chileno les brinda. El problema no es el actuar de las empresas, el verdadero problema es la negación de los derechos de los pueblos indígenas por parte del Estado chileno. Si éste reconociera los derechos, muy probablemente las empresas, en su lógica legalista, tendrían mejores relaciones con los pueblos indígenas.

Un caso particular es el de algunas empresas privadas extranjeras. Dependiendo del país o su matriz, algunas tienen protocolos o políticas de derechos humanos que reconocen un estándar mucho más elevado que el promedio de las empresas privadas chilenas o incluso que el propio gobierno de Chile. Estas empresas son las llamadas a cambiar el status quo de las relaciones entre empresas y pueblos indígenas. Están recién llegando e interiorizándose de la realidad del pueblo mapuche, hay uno que otro caso de asociatividad exitoso, pero aún es un tipo de relación que se está gestando.

En donde sí están al debe las empresas privadas chilenas y extranjeras es en tratar de entender y reconocer al pueblo mapuche - con talleres de inducción o planes de formación para los trabajadores y directivos de las empresas- como algo más que stakeholders beneficiarios de políticas de responsabilidad social de las empresas. Para cambiar el status quo, las empresas deben reconocer la existencia de territorios indígenas en disputa, pasar del bono a la participación en los beneficios e incluso in-

31. Sistema de salud mapuche. 
corporar a personas indígenas en la dirección misma de las empresas. No sé si exista un estudio sobre directorios y pueblos indígenas, pero es muy probable que ninguna de las empresas que cotizan en el IPSA y que tienen inversiones en el territorio mapuche tengan directores o altos ejecutivos que sean mapuches. Eso es algo que debe terminar.

\section{Verónica Figueroa}

Yo diría que, en ese sentido, la legislación chilena $-\mathrm{y}$ si bien el Instituto Nacional de Derechos Humanos ha hecho un esfuerzo por sacar informes anuales y dar cuenta obviamente de la realidad de los pueblos indígenas-, dejaría en claro que la ley es bien poco punitiva y poco controladora respecto de las empresas. Por lo tanto, con las empresas externas y extranjeras mineras, forestales, hídricas, etcétera, terminamos dependiendo mucho de su buena voluntad y de su sentido de responsabilidad social. Todo porque hay empresas que, por ejemplo, tienen dentro de su política ser más considerados o ser socialmente más responsables, puede ser que tengan un comportamiento más respetuoso con las comunidades en las cuales se insertan, entendiendo que el paraguas jurídico chileno es muy permisivo en ese sentido y, por lo tanto, dejamos mucho al comportamiento individual de cada empresa.

Lo anterior ha generado muchos conflictos entre comunidades, porque quizás una empresa A que tiene mayor responsabilidad social genera un vínculo recíproco y más igualitario con la comunidad y, por otro lado, una empresa $B$ sin responsabilidad social tiene un comportamiento mucho más nefasto, tratando a dos comunidades en un mismo territorio de manera distinta.

El Estado tiene que poner siempre un piso mínimo y un estándar. Las empresas extractivas extranjeras, más allá de sus mecanismos de mayor responsabilidad social o de sus intenciones en procesos más limpios de explotación, menos contaminantes, ya que no han sido del todo respetuosas con los derechos humanos de las comunidades, con los derechos de consulta de las comunidades, deben ser reguladas. Esto se relaciona, además, con que, a propósito del sistema de evaluación de impacto ambiental, siempre se ha intentado hacer una especie de ruta corta en todo lo que tenga que ver con los procesos de inversión, porque Chile tiene su matriz de crecimiento que es tan básica y poco sofisticada, en que el 90\% de sus exportaciones son materias primas, entonces se acaba el negocio si te pones más quisquilloso con el comportamiento que deberían tener las empresas y, por supuesto, con las empresas chilenas aún más, porque son holdings, un grupo de familias muy reducido que tiene el control de la extracción de todas estos recursos. Por ello, es muy difícil que cambien su comportamiento, menos si no existen incentivos.

En este sentido, el Estado tiene que ser emprendedor. El Estado debe generar los incentivos para aquello. Sin embargo, bajo la lógica de la subsidiaridad, de dejar que 
el mercado se autorregule, funcione y se intervenga exteriormente lo menos posible, se han ido generando estos espacios que han invisibilizado el mundo indígena y que han sido abordados más bien desde el punto de vista medioambiental, incluso por algunas organizaciones medioambientales, desconociendo el tema de derechos que están siendo pasados a llevar o no respetados. En cuanto pueblos indígenas, por supuesto que el equilibrio medioambiental forma parte de estas cosmovisiones, pero es mucho más compleja la cosmovisión indígena que solamente un equilibrio con el territorio, pues tiene que ver con una supervivencia cultural, política y ancestral y todos estos temas no han sido considerados.

Por ejemplo, con la discusión del TTP11, que en términos particulares se enfoca al tema indígena, pero desagregando podemos darnos cuenta que hay un patentamiento de un conocimiento tradicional que se va a ver afectado por este tratado y por otros tratados internacionales también.

No existe conocimiento de las empresas que intervienen en las comunidades de los derechos humanos de los indígenas, yo diría que salvo los equipos jurídicos que se limitan a conocer la norma y no transgredirla. No existen mayores exigencias legales a las empresas referidas a este tema, por eso es importante el rol que puede jugar el Estado como emprendedor, en tanto promueva de manera activa un comportamiento responsable de las empresas, pero no desde una buena voluntad, sino que debe generar un marco normativo sancionatorio para ello.

Pero si no se toma de manera seria a los pueblos indígenas, hay que avanzar en que las empresas efectivamente conozcan los derechos de los pueblos indígenas y que sean respetuosos en su actuar de acuerdo con los estándares que Chile ha suscrito. Cuando uno dialoga o escucha muchas veces a representantes del sector minero, las empresas mineras, no hay mucho respeto por los pueblos indígenas, porque por ejemplo hablar de conocimientos ancestrales ya es mirado como algo folclórico, hablar de derechos indígenas es hablar en la medida de lo posible, diría yo.

\section{Pregunta 4. Conflictos}

¿Qué salidas cree que existan para los conflictos entre el Estado de Chile y el pueblo mapuche, o algunos de sus miembros?

\section{Margarita Calfío}

Los conflictos deben ser enfrentados, porque constituyen oportunidades para avanzar en el diálogo y el respeto a los derechos humanos del pueblo mapuche.

La garantía inicial para avanzar en el actual escenario es la desmilitarización de los territorios y la no aplicación y anulación de todos los procesos judiciales en que se aplica la ley antiterrorista. Así lo ha señalado el Relator Especial sobre la Promoción 
y Protección de los Derechos Humanos y las Libertades Fundamentales en la Lucha contra el Terrorismo, cuando expresa su preocupación por la aplicación de la legislación antiterrorista a los participantes mapuches por la reivindicación de tierras, al considerar la aplicación de esta legislación como causa del problema y no de la solución, y por el uso excesivo de la fuerza por agentes de Carabineros y la Policía de Investigaciones en redadas o allanamientos de las comunidades mapuches y la detención de sospechosos, junto con la falta casi total de responsabilidad por los delitos de violencia excesiva contra los mapuches durante esos allanamientos.

Luego de este gesto de humanidad, debe primar el diálogo extenso y que fluyan los acuerdos políticos entre personas respetables. Que exista la real voluntad de que el pueblo mapuche se desarrolle integralmente y que no se siga estigmatizando a quienes reclaman con justo derecho la restitución de los territorios, porque fueron despojados de forma fraudulenta. Los procesos de diálogo son protocolares y obedecen a tiempos más largos para llegar a acuerdos que sean sostenibles y que se respeten integralmente. Todos los diálogos deben ser hechos de buena fe y con los tiempos necesarios para llegar a todas las familias de los extensos territorios, tanto urbanos como rurales.

Como establece el informe del Relator Especial sobre la Extrema Pobreza y Derechos Humanos: «Los derechos de los pueblos indígenas son el talón de Aquiles del historial de Chile en lo que respecta a los derechos humanos en el siglo XXI [...] Si el gobierno se propone seriamente acabar con la extrema pobreza y reducir la desigualdad, la política sobre cuestiones indígenas debe constituir un elemento esencial». ${ }^{32}$

El Comité de la CEDAW, en sus observaciones sobre el séptimo informe periódico universal de Chile, valora como positiva la propuesta de crear un ministerio de los pueblos indígenas. No obstante, le preocupa que las mujeres indígenas se enfrenten a una intersección de formas de discriminación basadas en el origen étnico y social, además de odio racial, la violencia basada en el género, la pobreza y la marginación. ${ }^{33}$

El Comité se mostró particularmente preocupado por los conflictos en algunas zonas del país que afectan a pueblos indígenas y la falta de reconocimiento y protección de la tenencia de la tierra y la propiedad por parte de las mujeres indígenas, el desalojo forzoso de sus tierras tradicionales indígenas y su exclusión de los procesos de toma de decisiones relativas al uso de la tierra; la ausencia de consultas efectivas y mecanismos para garantizar que las mujeres indígenas den su consentimiento libre, previo e informado para proyectos de desarrollo en sus tierras tradicionales.

32. Naciones Unidas, «Informe del Relator Especial sobre la extrema pobreza y los derechos humanos sobre su misión a Chile», A/HRC/32/31/Add.1, p. 15.

33. Comité para la Eliminación de la Discriminación Contra la Mujer, «Observaciones finales sobre el séptimo informe periódico de Chile», $\mathrm{CEDAW/C/CHL/CO/7}$, párrafo 46. 


\section{Venancio Coñuepan}

Respondiendo a la pregunta de cómo salir de los conflictos entre el Estado de Chile y el pueblo mapuche, creo que mientras no se reconozca la responsabilidad del Estado en la expoliación del territorio mapuche, no tenemos ninguna posibilidad de avanzar en solución alguna al conflicto. Por otro lado, la experiencia dice que son muy pocos los Estados los que reconocen voluntariamente su responsabilidad en procesos como éste y, por tanto, la solución a nuestro conflicto estaría bien lejos. En países como Canadá, Australia y Nueva Zelanda, los cambios fueron precedidos por demandas judiciales en sus respectivas cortes supremas, sólo eso ha producido cambios sustanciales en el tratamiento de los Estados con los pueblos indígenas. Quizás en el caso chileno, el único camino que nos pueda llevar a la reconciliación y la paz es una demanda y fallo favorable en la Corte Interamericana de Derechos Humanos.

Saliendo -o en paralelo al- del conflicto territorial, el más antiguo y el que más conflictividad genera, el Estado chileno y las sociedades civiles chilenas y mapuches deberían trabajar por la reconciliación de nuestros pueblos. La historia de estas tierras han sido mayormente de paz, pero esa paz requiere previamente reconciliación: conocernos, entendernos, aceptarnos, querernos, escucharnos. Sólo así podremos avanzar en las reformas que se requieren para establecer el marco jurídico necesario para una convivencia que permita la autodeterminación del pueblo mapuche dentro del Estado chileno.

El primer paso de esta reconciliación debiese ser un reconocimiento constitucional del pueblo mapuche, en el que se reconozcan de forma explícita los derechos que ya han sido reconocidos en instrumentos internacionales, como el Convenio 169 de la OIT o la Declaración de las Naciones Unidas sobre los Pueblos Indígenas, y comenzar una gradual implementación de dichos derechos. Pero como dije previamente, la historia de Chile es la de un indigenismo simulado que poco y nada reconoce de los derechos indígenas. Así que nos queda el camino de la judicialización nacional e internacional, como el camino más lento, pero más efectivo.

\section{Verónica Figueroa}

Creo que es complejo, porque aquí hay algo que no se quiere, toda vez que aquí hay un pueblo o pueblos que tenían una preexistencia en este territorio y que tenían un derecho, no desde la lógica occidental claramente, pero sí podemos decir que tenían una institucionalidad preexistente que la instalación de estos Estados aplacó totalmente, que no reconoció; por lo tanto, existe un trabajo pendiente por parte del Estado, que sería reconocer esta preexistencia y por supuesto determinar desde la perspectiva de derechos qué significa esta preexistencia y cuáles serían sus implicancias. 
Sin duda, uno de los temas más álgidos — además del reconocimiento de la diversidad, el reconocimiento en el territorio de este Estado o la participación dentro de éste- es el tema territorial. Es el tema clave hoy en día, ya que, de hecho, se asoma precisamente a partir del fracaso del proceso de la consulta indígena en curso, ${ }^{34}$ ya que la tierra es un sustento político y no un factor productivo como en la lógica win$g k a$; no es tierra, trabajo y capital la lógica que se sigue, sino que, bajo los paradigmas ancestrales, hablamos de mucho más, ya que la tierra es mucho más que tierra; cuando hablamos de territorio se relaciona directamente con la dimensión del ejercicio de las autoridades ancestrales, políticas, de sistemas de aplicación del derecho mapuche y de una forma de vida, no solamente se trata del equilibrio territorial. Se trata de una cultura que tiene una estructura.

Yo veo muy difícil una salida, sobre todo considerando las lógicas que vienen desde el Estado, las cuales se ven influenciadas por prácticas partidistas. Ellas terminan siempre en pedir perdón y reconocer la deuda histórica. Sin embargo, eso es sólo el inicio, ya que debe considerarse lo que viene después y cómo se generan efectivamente los cambios. Yo diría que desde el mundo indígena no hemos visto una creación de alguna institucionalidad, de un programa, de una corporación o una voluntad cierta por parte del Estado de generar cambios. Considero que eso hasta el momento realmente no existe.

La primera tarea es reconocer, basándose en la preexistencia. Segundo, generar los cambios institucionales estructurales para dar cabida a ello; y eso supone un cambio cultural, pues requeriría entonces que ya no hubiese cuestionamientos a que en los colegios se enseñe mapudungun, ${ }^{35}$ por ejemplo; tampoco se puede cuestionar que debemos conocer cuál es la estructura institucional política de los pueblos indígenas, cuál es la propuesta política de los pueblos, y sentarse a conversar en base a ella, transformarla y de alguna manera correr el cerco institucional político para que ello ocurra; y, por supuesto, dejar de hablar en términos de ampliación de tierra, sino de una política de restitución territorial y avanzar en la lógica de la autodeterminación, dando espacio a la autonomía y al autogobierno, no en la medida de lo posible, sino que haya un cambio efectivo del paraguas, para que lo anterior tenga una expresión cierta.

El pueblo mapuche parlamentó con la Corona española, el Estado chileno nunca acogió a nadie - de hecho, nunca estuvo dispuesto a dialogar-, y cuando han estado

34. Se refiere a la llamada consulta indígena para mejorar y adecuar la Ley 19.253, desarrollada por el gobierno desde mayo de 2019. Para la información oficial sobre la consulta indígena, véase http:// consultaindigena2019.gob.cl; para un perspectiva crítica, puede consultar la página de Facebook del Observatorio Crítico de la Consulta Indígena, https://www.facebook.com/ObsCriticoConsulta169.

35. Mapudungun, mapuzungun, mapuchedungun, mapunchedungun, chedungun, tse sumun, son diferentes denominaciones territoriales que se le da a la lengua propia del pueblo mapuche. 
dispuestos a hacerlo, lo han hecho bajo sus propios términos, lo que ellos consideran como posible y efectivo, con los temas que a ellos les interesa tratar, por lo que difícilmente puede haber confianza cuando eso ocurre.

\section{Pregunta 5. Recuperación de tierras}

¿Cómo debería resolverse la demanda de recuperación de tierras y territorios mapuches?

\section{Margarita Calfío}

Debería resolverse con real voluntad política de solución, con recursos y conocimientos de la historia mapuche, asumiendo que la tierra constituye el corazón del pueblo mapuche, su razón de ser. Mapuche significa gente de la tierra, gente interconectada con la tierra de forma profunda, conexión insondable que viene desde la antigüedad. Lamentablemente, con el paso de los años y los malos gobiernos, se han usurpado miles de hectáreas y miles de personas mapuches están en la miseria.

En segundo lugar, es necesario revisar los casos de conflictos desatados y latentes en base a estudios acabados, si existieron formas fraudulentas, engaños, bajo presión. De ser así, se deben devolver las tierras usurpadas como prioridad.

En los casos en que la devolución de tierras no sea posible, debe conformarse consejos que logren acuerdos y avances concretos. No existirán avances en un contexto de represión, enfrentamientos, violencia, y los conflictos obstaculizan el diálogo e impiden el acercamiento entre las partes y la generación de acuerdos constructivos. Estos acuerdos se logran en paz, y en este sentido, la Declaración de Naciones Unidas sobre Pueblos Indígenas ha reconocido el derecho colectivo de éstos a vivir en libertad, paz y seguridad:

Artículo 7.2: Los pueblos indígenas tienen el derecho colectivo a vivir en libertad, paz y seguridad como pueblos distintos y no serán sometidos a ningún acto de genocidio ni a ningún otro acto de violencia, incluido el traslado forzado de niños del grupo a otro grupo.

La realidad de Chile, por su parte, nos muestra que no existe un contexto adecuado de respeto, seguridad e integridad en que los pueblos indígenas puedan ver garantizados sus derechos humanos. Tampoco existe una institucionalidad moderna con recursos frescos, que podría ser una oportunidad real para dar un gran paso de conciliación y construcción de una nueva relación con los pueblos indígenas. Tampoco el desarrollo de competencias interculturales en Chile de forma permanente y transversal. 


\section{Venancio Coñuepan}

Creo que existe un problema basal que no permite resolver la cuestión de tierras y territorios mapuches. Se trata de algo absurdo pero real: primero, el Estado chileno no reconoce la existencia de un conflicto con el pueblo mapuche y, segundo, tampoco reconoce la existencia de una demanda territorial con base en un título de dominio original anterior al Estado chileno. Un tercer problema adicional, que no es absurdo pero sí muy complejo, es que la propiedad mapuche es diferente a la «propiedad indígena» y siento que no se ha dado esa discusión al interior del pueblo mapuche.

Primero, el Estado chileno no reconoce la existencia de un conflicto con el pueblo mapuche. Prueba de ello es que en las últimas décadas los distintos gobiernos han abordado el tema como si se tratara de una cuestión de mera pobreza, o un problema que fue creado por los españoles hace 500 años, como dijo la presidenta Bachelet hace unos años. El conflicto chileno-mapuche, fue creado por el Estado chileno cuando a mediados del siglo XIX desconoció diferentes tratados que regulaban la relación y comenzó a ocupar militarmente el territorio mapuche, dictó legislación para constituir la propiedad en un país diferente y finalmente, violando la propia ley chilena, ${ }^{36}$ y expolió el territorio mapuche. Esa es una historia que ha sido sistemáticamente negada hasta hoy, y no es extraño escuchar a un ministro o presidente decir que el conflicto recién comenzó en el año 1997 con los eventos de Lumaco.

Segundo, en el ordenamiento jurídico chileno se reconoce tan solo una propiedad que se dice indígena. Sin embargo, ésta no es más que la propiedad común que tiene una persona de calidad indígena o una comunidad indígena. Por tanto, la única diferencia entre la propiedad indígena y no indígena, es que la primera tiene las restricciones del artículo 13 de la Ley 19.253. La propiedad mapuche es muy distinta a la civil. La diferencia entre la propiedad mapuche e indígena es similar a lo de «empresa mapuche» $\mathrm{y}$ «empresa de mapuches». En la propiedad mapuche está o debería estar incorporado el mapuche kimün, en especial la relación de los che, con el mapu, con

36. Al respecto, cabe destacar que el espíritu de la primera ley de radicación, la Ley del 4 de diciembre de 1866 , reconocía que el título de dominio original mapuche estaba en los parlamentos que se habían firmado previamente tanto con la Corona española con la República de Chile y no en era el Estado chileno quien transmitía la propiedad a los mapuches, es decir, el Estado chileno no creaba la propiedad mapuche, sino que tan solo ratificaba una situación jurídica preexistente. Al respecto, en la discusión parlamentaria de 1865, el diputado Amunategui dijo: «Los varios parlamentos que desde siglos vienen fijando nuestras relaciones con los araucanos, contienen solo disposiciones generales, de carácter poco preciso. Sin embargo, el espíritu de ellos ha sido siempre que los españoles o cristianos debían respetar las propiedades de los indígenas, cualquiera que fuese la manera especial como las hubiesen constituido. Tales antecedentes obligan a las autoridades chilenas a aplicar, en cuanto sea posible, a las propiedades araucanas los principios protectores de la propiedad que se encuentran consignados en la ley fundamental del Estado» (Cámara de Diputados, Sesión Ordinaria 9, del 6 de julio de 1865, p. 90). 
los newen, ngen y ngünen, relación que hace a la persona como mapuche propiamente tal. Relación especial entre los pueblos indígenas y los territorios que es protegida por el derecho internacional de los pueblos indígenas. Esta propiedad es la que reconoce el estándar internacional del derecho de los pueblos indígenas, sobre todo después caso Awas Tingni de la Corte Interamericana de Derechos Humanos.

Por otro lado, la propiedad indígena es la que reconoce la legislación chilena, pero esta propiedad que se dice indígena es más bien la "propiedad civil común», cuyo dueño es una persona con calidad indígena o comunidad indígena, propiedad que no reconoce la relación del che con el mapu. Y que el artículo 12 de la Ley 19.253 la hace depender directamente de títulos de dominio que tienen su origen en la legislación chilena, desconociendo el título de dominio original basado en la posesión inmemorial que tenían los mapuches sobre su territorio. Esta sistemática negación es la que provoca y mantiene el conflicto entre el territorio mapuche con el Estado chileno. Mientras no se reconozca este título indígena pretérito al origen mismo del Estado chileno, vamos a tener un conflicto entre chilenos y mapuches.

\section{Verónica Figueroa}

Quiero reiterar que la política de restitución no es una política segmentada, no pasa simplemente por un fondo en que «vamos entregando tierras», sino que es una política que tiene que estar incrustada en todo el tejido institucional, si no se entiende de esa manera va a ser sólo eso: subsidios, emprendimiento o arrendamiento de tierras, siguiendo la lógica productiva. No ha habido una voluntad del Estado para clarificar qué es el territorio para el mundo indígena. Esto radica fuertemente en la poca profundización sobre el tema, en tanto se siguen prácticas en las que, por ejemplo, escuchando a uno o dos expertos ya nos consideramos competentes en la temática indígena y, por lo tanto, se cree que por haber hablado con diez comunidades indígenas diferentes en las que éstas exponen sus necesidades, y donde sólo se consideran aquellas cuestiones inmediatas - como, por ejemplo, la construcción de un puente o de un camino-, no se concentran las energías en las discusiones políticas, porque se ignoran o se prefiere priorizar otras cuestiones, aunque sean, por supuesto, necesidades muy sentidas por las comunidades. Hay que tener presente que el asunto político no acaba ahí y esa voluntad de dar profundidad a lo que es la restitución territorial es lo que falta.

Esto no se cambia modificando la ley, sino que se relaciona directamente con entender al territorio desde una perspectiva más amplia a lo limitado que puede establecerse en una ley. Por tanto, es necesario mostrar cómo la compresión del territorio desde esta concepción indígena puede plasmarse en la Constitución y luego permear toda la institucionalidad. 


\section{Pregunta 6. Mujeres mapuches}

¿Cuál es el papel que desempeñan las mujeres mapuches en las reivindicaciones de los derechos de su pueblo?

\section{Margarita Calfío}

En el último tiempo las mujeres han sido las protagonistas de luchas específicas por la sobrevivencia, por la recuperación de territorios usurpados, Por esto, mujeres mapuches han sido tomadas prisioneras, golpeadas brutalmente y torturadas, pero pareciera que a pocos les importa.

Hace algunos días, mujeres mapuches denunciaron públicamente que Fuerzas Especiales de Carabineros las detuvo injustificadamente y reprimieron con golpes de puño, patadas y lumazos mientras les gritaban que no reclamaran porque «a ustedes les gusta que les peguen, por eso están acá, son como animales», ${ }^{37}$ en el marco de una marcha por la defensa de las tierras ancestrales en Cañete. Ésa es la visión que tiene Carabineros de Chile de las mujeres mapuches, esa visión es violenta e irracional, cargada de odio.

Las mujeres mapuches por largos periodos han soportado muchos atropellos, dejando su dignidad de lado en muchos casos, por la cohesión mapuche, a pesar de las múltiples fracciones que se han producido por el paso del tiempo y situaciones externas internas que nos debilitan.

Las mujeres mapuches de corrientes más feministas en el último tiempo se están organizando con mayor fuerza, demandando una «reconstrucción» de la sociedad, un orden diferente, en el que no existan dominantes y dominados. Que no importe el género y que la fluidez de las relaciones y del género sean comprendidas y aceptadas. Debilitar las inevitables jerarquías que encuentran en el capital y el pensamiento anclado en categorías binarias.

En lo mapuche, el concepto yafvluwaiñ alude a darnos apoyo, fortaleza, estar firmes, con buena salud. Este significado es bien amplio y complejo, teniendo mayor belleza cuando se lo relaciona al mundo femenino mapuche, porque su trasfondo alude a la salud y la salud proviene de la naturaleza, que está más vinculada a lo femenino. Ella, la Madre Tierra, nos entrega salud con todo lo que nos provee. La mapu es todo para el pueblo mapuche.

Yafvluwain también alude a darse apoyo, fortaleza, nunca solas, interactuar en red; es importante que se conozca y que circule, en especial entre mujeres de diversas generaciones. Esta palabra es liberación, tiene una connotación potente porque nues-

37. “"No se quejen si ustedes son como animales": Mujeres mapuche denuncian golpiza de Carabineros durante marcha en Cañete», El Desconcierto, 21 de mayo de 2019, disponible en http://bit.ly/2YrIoTY. 
tro pueblo funda su existencia también en la palabra, el poder de las palabras, que nacen de la naturaleza, el habla de la tierra. Para rearmarnos, para seguir desafiando los presagios malos, para seguir buscando en el cielo los buenos augurios que nos marcan un nuevo futuro, con el protagonismo ahora de las mujeres, ese matriarcado que debe aflorar con urgencia para recomponer el sistema decadente.

¿Qué está pasando ahora? Las mujeres mapuches están siendo perseguidas y asesinadas, como es el caso de Macarena Valdés, lo femenino atacado, las tierras depredadas, la machi Francisca Lincaonao fue sometida a tres juicios, la vida está siendo violentada, amenazada. En la cosmovisión o forma de vida ancestral mapuche las mujeres eran valoradas en términos espirituales y simbólicos, son valiosas para la cohesión social del lof, todo el colectivo, y constituyen el despertar comunitario.

\section{Venancio Coñuepan}

Hay que distinguir dos escenarios, a saber, el mundo mapuche tradicional y el indígena contemporáneo. En el primero, los fütakeche $e^{38}$ me han enseñado que el papel que desempeñan hombres o mujeres no es determinado por el género, sino que confluyen otros factores relacionados con el mapuche kimün, como el küpalme, ${ }^{39}$ el tuwün ${ }^{40} \mathrm{y}$ sobre todo los püllü. ${ }^{41}$ Por ejemplo, en el caso de las y los machi, pareciera ser que en su mayoría son mujeres, pero hay territorios en donde los machi son principalmente hombres. En ese caso no es relevante el género de los che, sino que lo esencial es la existencia de un püllü de machi, un püllü que puede ser femenino o masculino.

Pero fuera del mundo mapuche tradicional, en la warria ${ }^{42}$ en las organizaciones indígenas, en el movimiento indígena mapuche contemporáneo, creo que las mujeres están adquiriendo un protagonismo muy relevante, y está muy bien que sea así; las mujeres tienen las mismas capacidades que los hombres, pueden liderar igual o mejor que nosotros y prueba de ello es la nobleza que han mostrado diferentes mujeres defendiendo sus territorios, nuestros derechos y la dignidad del pueblo mapuche; tal es el caso de la machi Francisca Linconao, la machi Evelyn Campos Huenchulaf de Rañiñtuleufu, la lamngen María Curriao de Alto Bio Bio, la lonko Juana Calfunao de Cunco, la lamngen Ana Llao en $\mathrm{Ad} \mathrm{Mapu}^{43} \mathrm{y}$ anteriormente en el Consejo de Conadi, la lamngen Emilia Nuyado en la Cámara de Diputados, la lamngen Elisa Loncon en la academia, entre muchas otras destacadas pu lamgen. Mujeres que están ahí no por

38. Personas mayores, antepasados.

39. Es el nombre que muestra el origen y linaje de donde proviene la persona. Muestra también el territorio de la familia, su lugar de origen.

40. Lugar o territorio de origen.

41. Espíritu que existe fuera del cuerpo.

42. Ciudad o lugar urbano.

43. Organización política mapuche creada a principios de los años ochenta. 
cuotas ni por moda, son personas que se han ganado su espacio y la admiración de muchos por su propia historia y méritos.

Ahora bien, es complicado cómo pueden convivir estos dos mundos. Desde el mundo más tradicional, creo que es más fácil aceptar el mundo indígena contemporáneo, porque hay más respeto; pero a veces, algunas personas del mundo indígena contemporáneo, que poco tienen de mapuche kimün, creen que los mapuches somos iguales a los aimara, a los rapa nui, a los indígenas de Bolivia, Mexico o incluso iguales a los wingka. Para el mundo mapuche el o la mapu es masculina y femenina, también los árboles, los animales, las estaciones del año, los püllü, todo puede ser masculino o femenino, no existe lo uno sin lo otro, no está esa oposición entre lo masculino y lo femenino, son complementarios y dependientes uno del otro. Estas últimas personas no son muy distintas a aquéllos que critican a otros por promover políticas coloniales. Por cierto que debe haber límites en cuanto a las relaciones de género al interior del pueblo mapuche, no puede seguir aceptándose la violencia en contra las mujeres o cualquier otro tipo de violaciones a sus derechos humanos; sin embargo, en cuanto al rol que le compete dentro de la sociedad, es algo que está dentro de las competencias propias de la autodeterminación de cada unidad sociopolítica mapuche, sea una identidad territorial, un ayllarewe, ${ }^{44}$ un lof, una comunidad o asociación indígena o una familia, etcétera.

\section{Verónica Figueroa}

La participación y el liderazgo de las mujeres es fundamental, porque además tiene una expresión significativa en casos emblemáticos como en el caso de la machi Francisca Linconao, el asesinato de Macarena Valdés, el rol de las hermanas Berta y Nicolasa Quintreman, la lonco Juana Calfunao, hoy en día la propia diputada Emilia Nuyado, Ana Llao con su liderazgo territorial, las jóvenes que vemos en las zonas urbanas, quienes se encuentran buscando su identidad y construyendo una reivindicación identitaria.

Todo esto nos pone en un desafío importante, ya que las lamgen deben estar dispuestas a dar lugar a este liderazgo femenino abriendo los espacios de discusión. Por supuesto que los trawun ${ }^{45}$ que se están dando tienen que tener presencia femenina. Su participación no puede remitirse a dar el soporte operativo para que el trawun funcione, ya que tienen mucho que decir, cuentan con el conocimiento, tienen el liderazgo, tienen la fuerza y sabiduría, por lo que es imposible construir un movimiento mapuche sin las mujeres y sus liderazgos, haciendo hincapié en que debería

44. Ayllarewe o aillarehue era la agrupación política de lof que dominaba una comarca.

45. Es una reunión o asamblea de la comunidad o entre comunidades, en la que se toman acuerdos guiados por la sabiduría ancestral. 
darse en todos los territorios, no solo en los territorios ancestrales, sino que también en las ciudades.

En el fondo, hay ejes y reivindicaciones que nos unen y, entendiendo cómo hoy se desarrolla el mundo, no pueden ser construidas de manera unilateral. El mundo mapuche se encuentra construido en el entendimiento de la complementariedad, que pasa por entender que ya no es la misma que se entendía hace 200 o 300 años, ya que esta complementariedad se ha visto muy contaminada por el mundo occidental, en el que existe una jerarquía basada en el patriarcado que obviamente ha permeado las relaciones del mundo indígena, ya que hemos crecido y nos hemos educado en ese contexto, por lo que volver a la lógica ancestral de la complementariedad es difícil. Esto finalmente se materializa en entender al liderazgo femenino como un punto sustantivo en la lucha política: que no puede haber lucha política hoy en día sin esos liderazgos.

\section{Sobre los entrevistados}

Las respuestas a las preguntas del debate fueron enviadas por escrito por Margarita Calfío y Venancio Coñuepan. Por su parte, Verónica Figueroa fue entrevistada por Valentina Canales, asistente editorial del Anuario de Derechos Humanos.

Margarita Calfío Montalva estudió Servicio Social en la Universidad Tecnológica Metropolitana, Chile, y obtuvo el título de Asistente Social en 1996. También posee estudios de Magíster en Género y Cultura en la Facultad de Filosofía y Humanidades de la Universidad de Chile. Ha dedicado sus investigaciones y publicaciones al estudio de la historia y la situación de las mujeres mapuches y de pueblos originarios, poniendo especial atención a las relaciones entre géneros e interculturalidad, violencia y políticas públicas. Asimismo, durante sus años en Santiago, apoyó la organización política mapuche. Desde 1997, vive y trabaja en Temuco, donde ha continuado su labor de estudio y activismo a través de la Comunidad de Historia Mapuche y la Casa Autogestionada de Mujeres del Ngulumapu.

Venancio lemunahuel Coñuepan Mesías es miembro del küpalme Koñuepangue del lof Pitrako Peuchen, en las cercanías de la actual comuna de Chol Chol, región de La Araucanía. Es descendiente de pu ñizol longko, machi, rañiñelwe, kimche, ülmen, ministro, diputado, gobernador y concejales. Es licenciado en Ciencias Jurídicas de la Universidad Católica de Temuco, Chile, diplomado en Política Indígena, Interculturalidad y Autonomía de la Universidad Alberto Hurtado, Chile, y fundador de la Fundación Chile Intercultural y de Koyang Do Tank.

Verónica Figueroa Huencho es profesora asociada del Instituto de Asuntos Públicos. Administradora Pública de la Universidad de Chile, doctorado en Management Sciences de la Universidad Ramón Lull, España, y postdoctorada del Center for Latin American Studies de la Universidad de Stanford, Estados Unidos. Senadora 
universitaria en representación de los Institutos Interdisciplinarios de la Universidad de Chile para el periodo 2018-2022. Ella ha sido coordinadora del United Nations Global Compact, con sede en Barcelona, entre 2004 y 2006, directora de la Escuela de Gobierno y Gestión Pública de la Universidad de Chile, y consejera presidencial de Conadi. Desde el año 2008 hasta el año 2017 fue coordinadora de la Comisión de Modernización curricular de la carrera de Administración Pública. También ha dirigido la comisión que apoyó la creación de la carrera de Administración Pública de la Universidad de O’Higgins como parte de la labor de apadrinamiento que hace la Universidad de Chile a la creación de universidades regionales. Su línea de investigación principal es el proceso de formulación e implementación de políticas públicas indígenas en contextos de diversidad. 